\title{
Intermittent catheterisation for neuropathic urinary incontinence
}

\author{
M N DE LA HUNT, ${ }^{*} S$ DEEGAN,* AND J E S SCOTT \\ ${ }^{*}$ Royal Victoria Infirmary, and †Department of Surgery, University of Newcastle upon Tyne
}

SUMMARY Eighty six children with neuropathic urinary incontinence who had been treated by clean intermittent catheterisation for more than five years were reviewed. Eighty five had congenital lesions, and one traumatic paraplegia. During the day, $72(84 \%)$ patients were dry or had minor stress incontinence only, 11 were damp but controlled with pads, and only three were continuously wet. Eleven abandoned clean intermittent catheterisation, five because of poor control, four by choice despite good control, and only two because of deterioration of upper urinary tract disease. Most of them usually had bacteriuria, but only 32 developed occasional symptomatic infections. Urinary calculi occurred in six, epididymitis in three, and urethral problems in four. Upper urinary tract dilatation did not arise in a previously normal renal system in any patient during clean intermittent catheterisation.

Clean intermittent catheterisation was successful in controlling wetting with few serious complications, and was well tolerated. It remains the method of choice for the management of neuropathic urinary incontinence in such children.

Intermittent catheterisation as a method of managing early urinary retention after traumatic spinal cord lesions was advocated by Guttmann and Frankel. ${ }^{1}$ Lapides et al subsequently described the technique of clean intermittent catheterisation for long term management of neuropathic urinary incontinence. This was based on the concept that regular complete bladder emptying was more important than sterile technique in preventing symptomatic urinary tract infection. ${ }^{2}$ Many patients have since been managed successfully in this way, without the need for cumbersome appliances.

There have been many reports of the use of clean intermittent catheterisation in children with myelomeningocele, and the early results have been good..$^{3-6}$ This early experience has suggested that it is associated with a lower incidence of renal complications than urinary diversion ${ }^{78}$ and is the method of choice for managing children with neuropathic urinary incontinence, at least in the short term.

The aim of this study was to assess the practicability, efficacy, safety, and acceptability of long term clean intermittent catheterisation in children who had been treated for at least five years in this way.

\section{Patients and methods}

All children with neuropathic urinary incontinence who started clean intermittent catheterisation in this centre between 1977 and 1981 were studied.

Before starting the treatment each patient had an intravenous urogram, a micturating cystogram, and a cystometrogram. This enabled assessment of upper urinary tract dilatation and function, bladder and urethral function, and vesicoureteric reflux. Cystometrography was initially carried out using a simple technique with a balloon catheter connected to a central venous pressure manometer. Later, a size 5 FG side hole catheter connected to a strain guage was used to measure bladder pressure during filling through a second 5 FG catheter passed alongside it. Radiographic contrast was used, and the bladder screened during filling to determine the association between vesicoureteric reflux and pressure. Urethral pressure profiles were measured by taking a continuous pressure recording as the catheter was withdrawn slowly from an empty bladder while simultaneously injecting at $1 \mathrm{ml} /$ minute.

The patients and their parents were trained to catheterise using a clean but not sterile technique, as previously described. ${ }^{5}$ They were taught to pass the catheter by touch, and thus many were able to manage clean intermittent catheterisation despite severe deformity and visual handicap. Girls used firm polyethylene catheters and boys used Nelaton 
catheters. They were taught to rinse the catheter in fresh running tap water before and after use, and soak it in sodium hypochlorite solution overnight.

Patients were followed up at intervals of three months, and a sample of urine was taken for microscopy and bacterial culture at each visit. Prophylactic antibiotics were not used routinely. Intravenous urography was repeated every three years to reassess the condition of the upper urinary tracts. Further investigations were ordered as clinically indicated. In addition the patients were recalled to a specially arranged clinic for the purpose of this study at the end of the study period.

\section{Results}

A total of 86 children started clean intermittent catheterisation for incontinence during this period, and have been followed up for five to nine years. There were 46 boys and 40 girls, median age 11 years (range 4-16 years). Most had neural tube defects (80 myelomeningoceles, and three lipomeningoceles), one had sacral agenesis, one traumatic paraplegia, and one had an idiopathic neurogenic bladder. Forty had a sensory level above T12, 22 between L1 and L4, and 24 had sacral lesions. Thirteen were totally confined to wheelchairs, and 52 had limited mobility with calipers and crutches. Only 13 were able to walk without any form of appliance. Eight required some appliance or had markedly abnormal gait. Many had mild mental handicap, although only four were so severely affected as to be unable to be taught to catheterise themselves.

Before starting catheterisation 55 were using pads and diapers, 22 external appliances, 12 manual expression, four indwelling catheters, and one had had reversal of an ileal conduit urine diversion.

Seventy eight $(91 \%)$ had learned to catheterise themselves within two years of starting. Most catheterised every two to four hours during the day at regular intervals, but 30 recognised vague symptoms from bladder distension that helped them time the clean intermittent catheterisation. Only five woke up at night to catheterise. Older patients learned to catheterise more often while out drinking in the evenings. Girls found it more difficult to control incontinence during menstruation.

Twenty six patients $(30 \%)$ were completely dry day and night. Fifty (58\%) were completely dry during the day, and $22(26 \%)$ had minor stress incontinence only. Only three patients had problems with severe daytime wetting that was not controlled by catheterisation and pads. At night 32 were dry, and only 11 wet their bedclothes despite the use of pads.

Because of poor control despite two hourly catheterisation, 48 patients were tried on drugs (propanthelene bromide, imipramine, or oxybutynin). Improvement was recorded in 38. Side effects required reduction of the dose or the stopping of the drug in only five.

Symptomatic urinary tract infections were recorded occasionally in only 32 patients, though all but one frequently had bacteriuria and pyuria. Their symptoms were usually vague, consisting of general malaise, fever, discomfort during catheterisation, and poorer control of incontinence. Eight patients reported difficulty with inserting the catheter caused either by bladder neck spasm, balanitis, erections, or difficulty with balance. Two patients developed renal calculi and two had bladder calculi. Two further patients developed bladder stones along suture lines after bladder augmentation. Three boys had epididymitis, two had recurrent episodes of urethral bleeding, one developed a urethral stricture, and one a posterior urethral diverticulum.

Thirty two patients had hydronephrosis before starting clean intermittent catheterisation. On serial intravenous urography this was shown to improve in 13 , even in the presence of vesicoureteric reflux (table 1). Unilateral dilatation deteriorated in one patient with reflux after colonic bladder augmentation. Deterioration in two patients without reflux was attributed to poor bladder emptying. This was the result of catheter impaction in a posterior urethral diverticulum in one, and poor compliance in the other who was unable to catheterise himself more than twice daily. There was no radiographic evidence of deterioration in four patients who had reflux without dilatation before starting clean intermittent catheterisation, and dilatation did not arise in any previously normal renal system during catheterisation.

Initial urodynamic studies had little predictive value for these patients, but were useful in selecting those who could be helped by drugs. For the whole group, median bladder volume was $200 \mathrm{ml}$ (range 25-300), bladder pressure $20 \mathrm{~mm} \mathrm{Hg}$ (range 5-60), and urethral resistance $26 \mathrm{~mm} \mathrm{Hg}$ (range 5-60). There was no significant correlation between any of these measurements before starting clean inter-

Table 1 Outcome in patients with upper urinary tract dilatation before starting clean intermittent catheterisation

\begin{tabular}{lll}
\hline Outcome & $\begin{array}{l}\text { No with } \\
\text { reflux }\end{array}$ & $\begin{array}{l}\text { No without } \\
\text { reflux }\end{array}$ \\
\hline No change & 6 & 10 \\
Improvement & 7 & 6 \\
Deterioration & 1 & 2 \\
\hline Total & 14 & 18 \\
\hline
\end{tabular}


mittent catheterisation, and the final result in terms of continence and upper tract deterioration. Continence did improve in many who persevered, and urodynamic studies were not repeated routinely in such patients.

Nineteen patients underwent further urinary tract surgery after starting clean intermittent catheterisation (table 2). Bladder augmentation was successful in increasing bladder volume in all four patients, but failed to improve continence in two of them. Two of those who had artificial urethral sphincters were active paraplegic athletes who, although they had only minor stress incontinence, found that this severely limited their activities. Two boys whose bladder neck spasm made catheterisation difficult underwent transurethral sphincterotomy: one remained dry after the procedure and the other, who was damp before, was not made any worse. Two patients had nephrectomies, one for pyonephrosis secondary to renal calculi, and one for a nonfunctioning kidney secondary to obstruction by a bladder diverticulum present before starting clean intermittent catheterisation. The need for nephrectomy was not attributable to catheterisation in either patient. One patient has since had an ileal conduit urinary diversion in another centre after discharge from our clinic, although his incontinence was well controlled with catheterisation without upper urinary tract deterioration. One has had a perineal urethrostomy after developing a urethral stricture, and has since changed to indwelling catheter drainage (two years after starting clean intermittent catheterisation). One, in chronic renal failure before starting clean intermittent catheterisation, had a renal transplant.

Six patients died during the study period. One boy died at home aged 17, after four years of clean intermittent catheterisation. A diagnosis of renal failure secondary to bilateral hydronephrosis and

Table 2 Urinary tract operations carried out after starting clean intermittent catheterisation

\begin{tabular}{ll}
\hline Operation & No of patients \\
\hline Colovesicoplasty & 4 \\
Artificial urethral sphincter & 3 \\
Circumcision & 3 \\
Sphincterotomy & 2 \\
Nephrectomy & 2 \\
Ileal conduit diversion & 1 \\
Urethrostomy & 1 \\
Renal transplant & 1 \\
Nephrolithotomy & 1 \\
Bladder diverticulum & 1 \\
\hline Total & 19 \\
\hline
\end{tabular}

infection was made at necropsy. He had undergone transurethral sphincterotomy at the age of 5 for hydronephrosis, and had unilateral grade 2 vesicoureteric reflux when he started clean intermittent catheterisation. Another died during a rejection episode after renal transplantation. Two died from chest infections and two from the complications of hydrocephalus.

Sixty seven patients were pleased with clean intermittent catheterisation. Control of incontinence increased their self confidence, enabling them to participate in a wider range of activities. Four found it just satisfactory, and three thought it unsatisfactory but still preferred to continue with it rather than wear 'a bag'. It was abandoned in 11 patients: in two for upper tract deterioration, and five because of poor control of incontinence. Three, with good control of incontinence, did not like catheterisation, and preferred an appliance or indwelling catheter. One patient after four years clean intermittent catheterisation, learned to stay dry using only bladder expression.

\section{Discussion}

Most of the patients in this study were severely physically handicapped and many were also mentally subnormal. Some had tried various incontinence appliances but found it difficult to keep them on because of physical deformities, obesity, and orthopaedic appliances. Even those restricted to wheelchairs preferred clean intermittent catheterisation to other systems, and were pleased to be free from cumbersome appliances and bags.

There were no clear early predictors of success with clean intermittent catheterisation. Many who initially had poor control improved with time, possibly reflecting changes in bladder activity with prolonged catheterisation. We did not repeat urodynamic studies in such patients routinely, and are thus unable to verify this hypothesis from this study.

The overall rate of complications was low; in only two patients was it stopped for upper urinary tract deterioration. Though colonisation of the urinary tract by bacteria was common, symptomatic infections were rare. Similar findings of a comparatively low rate of symptomatic infection, despite a high incidence of bacteriuria, have been reported in other series. ${ }^{69}$ Only one of our patients died with acute on chronic urinary tract disease.

Compliance with the technique depends on many factors. All these patients face unique complex physical, emotional, and social problems. The attitudes of the patients, their parents, and those supporting the family seemed the most important predictive factors. Many found that clean intermit- 
tent catheterisation was actively discouraged, and adequate facilities not provided even in special schools for the disabled. Thus even some who had good control of incontinence chose to abandon clean intermittent catheterisation, while some who remained wet were grateful for small improvements.

This study confirms that clean intermittent catheterisation is a useful, acceptable, and safe technique for children with neuropathic urinary incontinence. Even the severely handicapped considered better control of incontinence led to a more active, useful, and enjoyable life.

\section{References}

${ }^{1}$ Guttmann L, Frankel H. The value of intermittent catheterisation in the early management of traumatic paraplegia and tetraplegia. Paraplegia 1966;4:63-83.

2 Lapides J, Diokno AC, Silber SJ, Lowe BS. Clean, intermittent self-catheterization in the treatment of urinary tract disease. J Urol 1972;107:458-61.

${ }^{3}$ Drago JR, Wellner L, Sanford EJ, Rohner T J Jr. The role of intermittent catheterization in the management of children with myelomeningocele. J Urol 1977;118:92-4.

${ }^{4}$ Withycombe J, Whitaker R, Hunt G. Intermittent catheterisation in the management of children with neuropathic bladder. Lancet 1978;ii:981-3.

${ }^{5}$ Scott JES, Deegan S. Management of neuropathic urinary incontinence in children by intermittent catheterisation. Arch Dis Child 1982;57:253-8.

${ }^{6}$ Uehling DT, Smith J, Meyer J, Bruskewitz R. Impact of an intermittent catheterization program on children with myelomeningocele. Pediatrics 1985;76:892-5.

${ }^{7}$ Lyon RP, Scott MP, Marshall S. Intermittent catheterization rather than urinary diversion in children with meningomyelocele. J Urol 1975;113:409-17.

${ }^{8}$ Crooks KK, Enrile BG. Comparison of the ileal conduit and clean intermittent catheterization for myelomeningocele. Pediatrics 1983;72:203-6.

${ }^{9}$ Kass EJ, Koff SA, Diokno AC, Lapides J. The significance of bacilluria in children on long-term intermittent catheterization. J Urol 1981;126:223-5.

Correspondence to Mr MN de la Hunt, Department of Paediatric Surgery, Royal Victoria Infirmary, Newcastle upon Tyne NE1 4LP.

Accepted 1 December 1988 